\title{
JOURNAL
}

of Health Inequalities

\section{Discrepancies in breast cancer management in Poland}

\author{
Michał Seweryn ${ }^{1,2}$, Tomasz Banaś ${ }^{3}$, Joanna Streb ${ }^{4}$, Rafał Matkowski ${ }^{5,6}$, Wojciech Wysocki ${ }^{7,8}$, \\ Joanna Augustyńska², Justyna Kopel², Ola Kizińska² \\ ${ }^{1}$ Associate of the Institute - European Observatory of Health Inequalities, Calisia University, Kalisz, Poland \\ EconMed Europe, Kraków, Poland \\ 3Department of Gynaecology and Gynaecological Oncology, Chair of Gynaecology and Obstetrics, Faculty of Medicine, \\ Jagiellonian University Medical College, Krakow, Poland \\ ${ }^{4}$ Chair of Clinical Oncology, Faculty of Medicine, Jagiellonian University Medical College, Krakow, Poland \\ ${ }^{5}$ Wrocław Medical University, Wrocław, Poland \\ ¿Lower Silesian Oncology Centre, Wrocław, Poland \\ ${ }^{7}$ Department of General, Oncological and Vascular Surgery, $5^{\text {th }}$ Military Clinical Hospital in Krakow, Poland \\ ${ }^{8}$ Chair of Surgery, Faculty of Medicine and Health Sciences, Andrzej Frycz Modrzewski Krakow University, Krakow, Poland
}

\begin{abstract}
Introduction: Breast cancer is one of the most frequently diagnosed neoplasms among women, and the number of cases is increasing every year. Although the incidence rate places Poland below the European Union average, the mortality rate shows that a problem with the diagnosis and treatment of breast cancer exists. We tried to answer whether the current path of a breast cancer patient in Poland is optimal, whether patients have access to all possible treatment options, and whether the treatment centre has a significant impact on the treatment method.

Material and methods: To achieve the study goals, we obtained data from the National Health Fund on the structure of procedures related to the treatment of breast cancer, and we conducted a survey in hospitals and performed individual in-depth interviews with experts.

Results: Among all hospitals in Poland, only 8\% (47 hospitals) implement at least 4 of the basic profiles of breast cancer treatment: oncological surgery, clinical oncology, radiotherapy, and access to tailored therapies. Only 9 centres in Poland were accredited as a Breast Cancer Unit. Most hospitalizations related to the treatment of breast cancer are carried out in oncology hospitals $(28.8 \%)$ and national hospitals (24.8\%). However, nearly $27 \%$ of hospitalizations took place in units with no more than the 2 nd-level of referentiality. The results of the survey and interviews with experts indicate that treatment of breast cancer patients, performed in centres with low reference levels, does not ensure an adequate level of treatment quality and coordination.

Conclusions: The right treatment path for a patient with breast cancer is a guarantee of long-term survival and high-quality treatment. Unfortunately, fragmentation of the oncological services in Poland means that there is still no oncological care system for patients with breast cancer that provides an equal level of care to patients regardless of the selected centre for treatment.
\end{abstract}

KEY WORDS: healthcare disparities, organization and administration, health services accessibility, breast neoplasm therapy, treatment outcome. 


\section{INTRODUCTION}

\section{EPIDEMIOLOGY}

Breast cancer is one of the most frequently diagnosed neoplasms among women, and the number of cases is increasing every year $[1,2]$

Based on the collected data from oncology registries participating in the European Network of Cancer Registries - the Joint Research Centre (ENCR-JRC) project and the International Agency for Research on Cancer (IARC) - the current (2020) incidence of malignant neoplasms for 27 countries of European Union (EU-27) was estimated [3]. Mortality data were taken from the WHO database [4].

The breast cancer incidence rate in Poland in 2020 was 119.1 (age-standardized rate, ASR), which means fewer cases compared to the European average (EU-27) - 142.8 per 100,000 (Fig. 1).

In turn, the standardized mortality rate in Poland in 2020 was 41.8 , which, compared to the European average of 34.1 per 100,000 , is one of the highest results. Among European countries, only Slovakia and Cyprus present higher breast cancer standardized mortality rates (Fig. 2).

These data, like other forecasts, show that the mortality rate due to breast cancer in Poland is in an upward trend $[2,5]$.

The European Statistical Office (Eurostat) provides estimates of the number of preventable deaths among European residents (2017 data) [6]. In other words, these are deaths that would not have occurred before the age of 75 years, thanks to appropriate prevention and the use of more effective methods of treatment. There are many more such deaths in Poland in total (age-standardized ratio $[\mathrm{ASR}]=355.5$, preliminary data for Poland for 2017) compared to European data $(A S R=253.5)$.

\section{TREATMENT OF BREAST CANCER}

In recent years, significant progress has been made in the development of diagnostic and therapeutic methods in breast cancer management. Perceptions of the potential for survival of breast cancer in patients and healthcare professionals have also changed. According to the guidelines of the European Society of Breast Cancer Specialists (EUSOMA), comprehensive care for patients with breast cancer should take place in profiled centres with a team of experienced specialists in various fields, including oncological surgeons experienced in breast reconstructive surgery, clinical oncologists, radiotherapists and radiologists, psycho-oncologists, and physiotherapists [7]. A very important factor that determines the effectiveness of breast cancer treatment is high-quality surgical treatment [8], especially because breast cancer is a heterogeneous disease, where a "one-size-fits-all" treatment approach is not appropriate anymore. There is often more than one surgical solution carrying equal oncological safety for an individual patient [9].

Following these standards, we tried to answer whether the current path of breast cancer patients in Poland is optimal, whether the patients have access to all possible treatment options, and whether the place where the services are provided has a significant impact on the treatment method.

\section{MATERIAL AND METHODS}

To achieve the study goals, we collected information from the National Health Fund (NHF) database about facilities performing procedures related to the treatment of breast cancer in Poland. In Poland the majority of hospitals are included in a network with several different levels of referentiality:

- general hospitals:

- $1^{\text {st }}$ level with 4 basic units: surgery, internal diseases, gynaecology and obstetrics, and paediatrics - mainly county hospitals,

- $2^{\text {nd }}$ level with 4 basic units plus 2 specialized units larger county and some city hospitals,

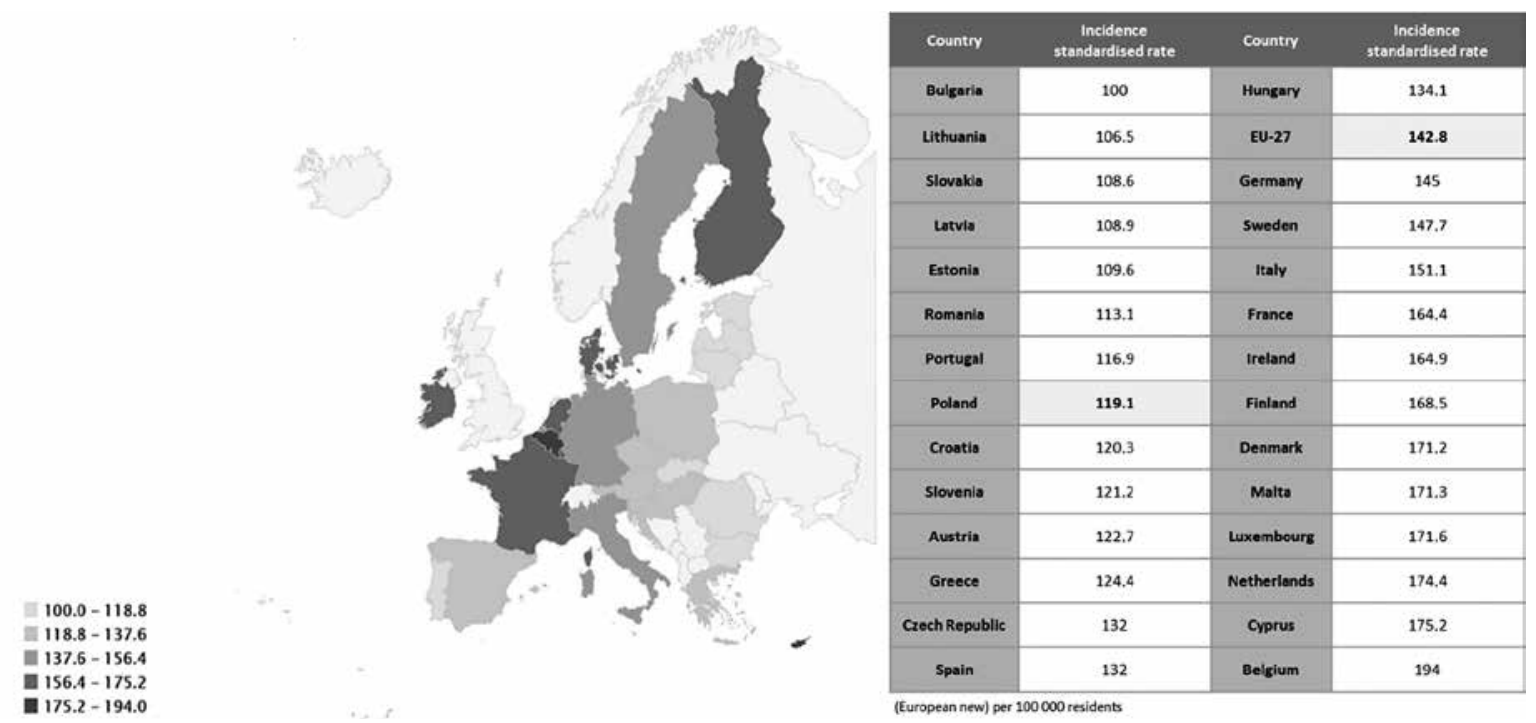

FIGURE 1. Breast cancer incidence in Europe (standardized rate) per 100,000 inhabitants in 2020 


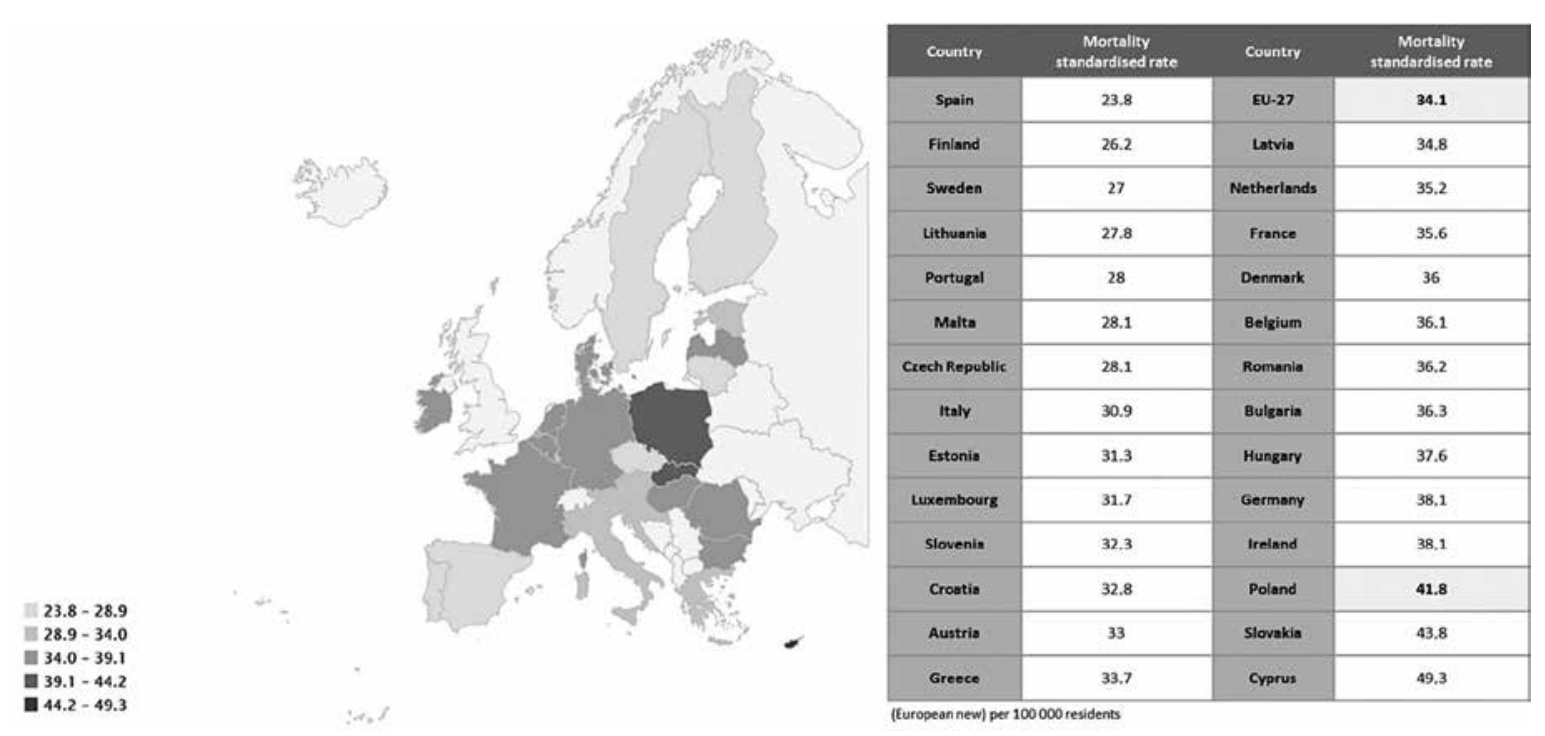

FIGURE 2. Breast cancer mortality in Europe (standardized rate) per 100,000 inhabitants in 2020

- $3^{\text {rd }}$ level with 4 basic units plus 6-8 specialized units - regional hospitals;

- specialized hospitals:

- children's hospitals,

- oncological hospitals,

- pulmonology hospitals.

- national hospitals - university hospitals and institutes.

Hospitals in the network are financed by general budgets assigned to them by NHF or they have guaranteed contracts with NHF, and $91 \%$ of the funds used for the total hospital financing is allotted to them. Hospitals that are outside the network may apply for contracts with the NHF, but only $9 \%$ of the overall funds are allocated to them.

We gathered NHF data on types of procedures related to breast cancer therapy: oncological surgery, clinical oncology, chemotherapy, radiotherapy, access to the latest drugs (contracted in Poland as a separate service called "drug program") were provided by the hospitals considering their level. We collected detailed quantitative data on hospitalizations in the DRG (diagnosis-related group) system relating to breast cancer treatment (named: J01, J02, J03E, J03F, and J04).

To identify potential differences in the methods of treatment of patients with newly diagnosed breast cancer, a questionnaire study was conducted on the diagnosis and treatment of breast cancer in Poland. It was addressed to the heads of hospitals/heads of surgical departments (if necessary, in consultation with doctors of oncology departments/ clinics). The answers were provided based on the data of patients with newly diagnosed breast cancer, who visited individual centres in 2019. The questionnaire was sent in both paper and online form. The questionnaire was sent to 53 healthcare entities, including $101^{\text {st }}$-level hospitals, $102^{\text {nd }}-$ level hospitals, $103^{\text {rd }}$-level hospitals, 10 national hospitals, and 13 oncology hospitals. Due to the current epidemiological situation in Poland, responses were obtained from six medical entities, including two oncology hospitals, two $3^{\text {rd }}$-level hospitals, one $2^{\text {nd }}-$ level hospital, and one $1^{\text {st }}$-level hospital.

Regardless of the survey, it was decided that we would conduct individual in-depth interviews (IDI) with medical staff and people responsible for organizational and financial aspects related to the care of patients with breast cancer. Due to the epidemiological situation, their form included online meetings (videoconferences) or telephone calls (teleconferences). Twenty respondents were invited to participate in the interviews; we managed to conduct them with 10 people.

The interview questionnaire was conducted from September to November 2020.

\section{RESULTS}

\section{STRUCTURE OF HOSPITALS AND UNITS}

Based on NHF data among all hospitals in Poland, only $8 \%$ (47 hospitals) implement at least 4 of the basic profiles of breast cancer treatment: oncological surgery, clinical oncology, chemotherapy, radiotherapy, and access to the latest drugs (drug program). Only $4 \%$ of them (23 hospitals) provide all possible services, of which more than half are oncology hospitals (52\%) and over $25 \%$ are national hospitals.

When analysing the services offered depending on the type of hospitals, a significant degree of dispersion of facilities is visible. Approximately $1 / 3$ of the $3^{\text {rd }}$-level hospitals provide hospital treatment services related to oncological treatment (32\% - oncological surgery, 37\% - clinical oncology, 35\% - therapeutic program - breast cancer treatment), but only $9 \%$ provide access to radiotherapy. Outpatient specialist care in the field of oncolo- 


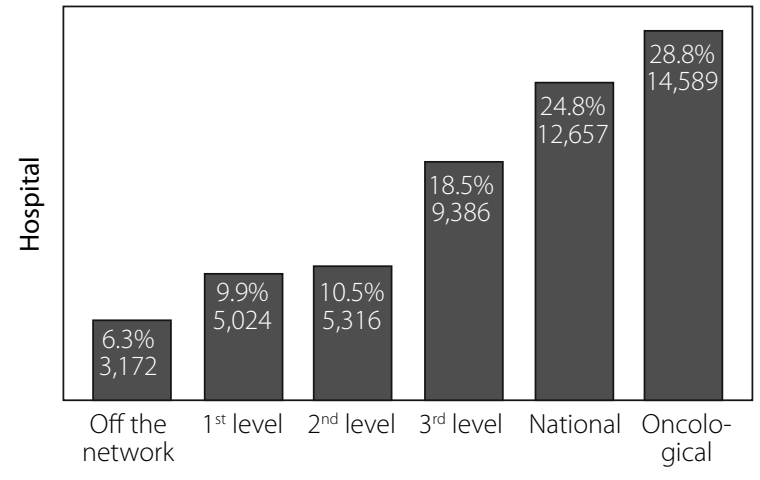

FIGURE 3. Hospitalizations related to the treatment of breast cancer by hospital level in Poland in 2019

gy is provided in $58 \%$ of $3^{\text {rd }}$-level hospitals, while in only $30 \%$ of oncological surgery hospitals. On the other hand, three-quarters of them provide chemotherapy services. In the case of $1^{\text {st }}-3^{\text {rd }}$-level hospitals, the issue of surgery looks best. Over $90 \%$ of $1^{\text {st }}-3^{\text {rd }}-$ level hospitals have general surgery departments, and $81-88 \%$ of these hospitals provide outpatient specialist services as part of general surgery (but it is not the same as cancer surgery).

It is interesting that nationwide hospitals perform slightly worse; less than $30 \%$ provide oncological care as part of hospital treatment at the highest level $(28 \%$ - oncological surgery, $22 \%$ - clinical oncology, $21 \%$ therapeutic program). More than half of the nationwide hospitals provide chemotherapy services, and just over 1 in 10 hospitals provide radiotherapy services. Outpatient specialist care in the field of oncology is provided by $41 \%$ of nationwide hospitals, while a quarter of these

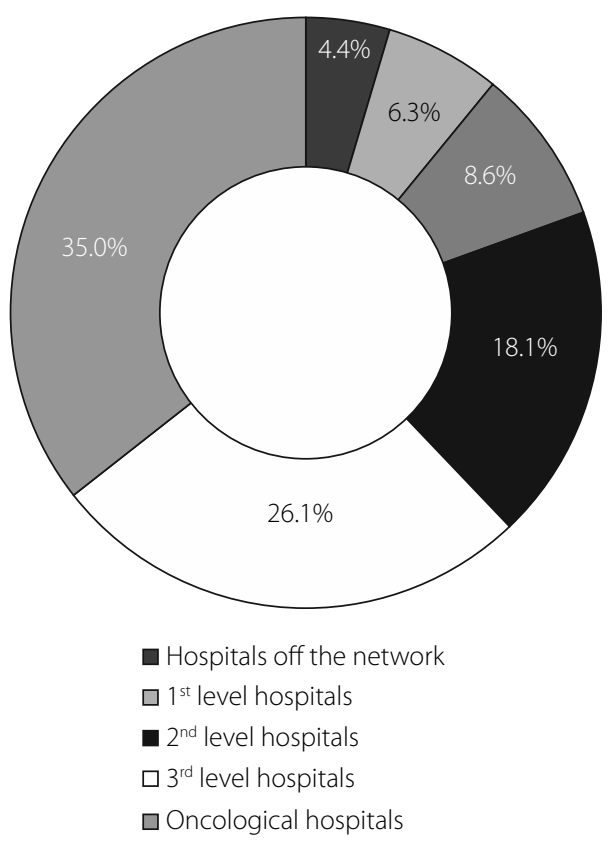

FIGURE 4. DRG hospitalizations related to the treatment of breast cancer by hospital level in Poland in 2019 hospitals provide advice as part of oncological surgery. Among nationwide hospitals, $70 \%$ and $71 \%$, respectively, provide care in this profile in hospital clinics and hospital departments.

In terms of the type of treatment offered, oncology hospitals are of course the best. In all hospitals of this level, a therapeutic program is implemented - treatment of breast cancer, outpatient specialist care in the field of oncology, and chemotherapy. Nearly 9 out of 10 hospitals provide access to radiotherapy and hospital treatment as part of oncological surgery. Also, the oncology hospitals have a clinical oncology ward, and $69 \%$ provide oncological surgery services on an outpatient basis.

It should be taken into consideration that $81 \%$ of hospitals outside the network, $70 \%$ of the $1^{\text {st }}$-level hospitals, and $43 \%$ of the $2^{\text {nd }}$-level hospitals do not provide any of the basic oncological treatment profiles (oncological surgery; clinical oncology chemotherapy, radiotherapy, therapeutic program). No hospitals outside the network and $1^{\text {st }}$-level hospitals, and only $6 \%$ of $2^{\text {nd }}$-level hospitals implement at least 4 of the above-mentioned profiles. However, no $1^{\text {st }}$-level hospital or hospital outside the network has the possibility of interdisciplinary treatment of breast cancer.

\section{STRUCTURE OF HEALTH SERVICES}

Most hospitalizations related to the treatment of breast cancer are carried out in oncology hospitals (28.8\%) and national hospitals (24.8\%). However, nearly $27 \%$ of hospitalizations took place in units with no more than $2^{\text {nd }}$-level of referentiality, of which nearly $25 \%$ of hospitalizations took place in hospitals outside the network (Fig. 3).

Despite the recommendations that comprehensive care for patients with breast cancer should take place in profiled centres, over 5000 hospitalizations (19\%), out of approx. 26,000 in the DRG groups related to the treatment of breast cancer (named: J01, J02, J03E, J03F, and J04) in 2019, were implemented in hospitals with no more than the $2^{\text {nd }}-$ level of referentiality, while slightly fewer $(4800,18.1 \%)$ were carried out in $3^{\text {rd }}$-level hospitals. Only $35 \%$ of hospital treatment cases took place in oncology centres (Fig. 4).

Analysing the available data in Poland, in 2019176 healthcare providers delivered 16,820 services in the field of breast cancer surgery (DRG groups J01 and J02) to patients diagnosed with ICD-10 C50: malignant neoplasm of the breast. Of these, 33 facilities performed at least 150 procedures, which corresponds to the minimum annual number of patients treated in Breast Cancer Units (BCU) following SIS (Senologic International Society) recommendations. These centres performed as much as $78 \%$ of all procedures. On the other hand, at least 250 procedures (as part of the oncology package and outside the package) were performed by 23 centres, providing 11,090 services, which constituted $66 \%$ of the 
total number of procedures. According to the recommendation, there should be an average of 1 centre specialized in the comprehensive treatment of breast cancer per 500,000 inhabitants, while in Poland there is one centre for approx. 1.2-1.7 million people, depending on the adopted criterion of the number of procedures performed (150 per year, 250 per year). Accessibility to the centres differs between regions (voivodships) of Poland. The worst situation is in the Lubusz Voivodeship, where there are no centres that perform at least 150 breast cancer surgeries. The voivodeships in which 1 centre is available for more than 1.5 million inhabitants are West Pomerania, Lesser Poland, and Kujawy-Pomerania. The best situation is in the Pomeranian (781,000 inhabitants per centre), Łódz (818,000 per centre), and Silesian (904,000 per centre) voivodeships, but these indicators still differ from the recommended ones.

\section{RESULTS OF THE HOSPITALS' QUESTIONNAIRE STUDY AND IDI WITH EXPERTS}

In 2019, half of the surveyed hospitals (including both oncology hospitals) admitted at least 200 patients with breast cancer, and fewer than 100 patients reported to only 1 hospital ( $1^{\text {st }}$-level). Eighty-three per cent of patients were treated in the centre to which they were initially sent. The most common reason why patients did not receive treatment was their resignation and referral to a centre with higher reference.

A comparison of the survey results between hospitals with different degrees of referentiality (despite a small research sample) showed that there are differences in treatment. Among other things, the answers of the respondents show the folowing:

More patients in targeted or mammotomy core biopsy had the tumour location marked (anchor, titanium marker) in oncology centres than in hospitals with a lower level of reference.

Neoadjuvant treatment was chosen more often as the first-line treatment in oncology centres than in $2^{\text {nd }}-$ level hospitals.

Mastectomy was the most frequently performed procedure for patients treated with neoadjuvant therapy in $2^{\text {nd }}$-level hospitals (over $75 \%$ of patients), while breast-conserving therapy was most often performed in oncology centres.

The table below presents a summary of the interviews conducted with the respondents and the most common arguments they made (Table 1 ).

The results of the interviews show that experts see the need for breast cancer treatment in BCU-type centres. In the case of facilities treating breast cancer "additionally", there is less chance of applying the latest standards. While some experts believe that it is justified for chemotherapy treatment to take place close to home, surgery should, in the opinion of the majority, take place in centres where the treatment of breast cancer is com- prehensive and coordinated. Most of the respondents agreed that it is necessary to implement diagnostic standards (especially in the field of genetic tests), which are often not optimally performed in some smaller facilities, also for "economic" reasons.

\section{DISCUSSION}

In the Polish oncological care system, there are many problems and challenges. One of them is that the waiting time for cancer treatment in Poland is too long. A study conducted on 1143 cancer patients treated at 6 medical centres in Poland showed that the waiting time for the treatment of cancer patients in Poland is too long exceeding 9 weeks in $60 \%$ of the cases [10]. The systemic change introduced in 2015, aimed at introducing a fast track for oncological patients, was associated with high hopes for doctors, experts, and, above all, patients [11]. Unfortunately, the results of the control carried out by the Supreme Audit Office [12] showed that not all medical entities provided services of the same quality; in some of the hospitals audited, patients were treated without complete immunohistochemical and molecular tests, which prevented patients from obtaining some of the available therapeutic procedures.

Our results confirm the conclusion that patients in hospitals with higher degrees of referentiality, who have a greater chance of transforming into a Breast Cancer Unit or similar, can offer a comprehensive spectrum of therapeutic options, thanks to which patients are significantly more likely to obtain optimal treatment results.

Moreover, the controlling authority stated that the introduction of the fast-track route for oncological patients did not improve the most important aspects of cancer treatment. This concerned the following: detection of the disease at the earliest possible stage, providing all patients with access to quick and coordinated diagnostics, as well as the use of optimal therapeutic procedures, ensuring comprehensive and high-quality services, allowing for the achievement of European patient survival rates.

Comprehensive patient care is the standard that oncological treatment aims to achieve in the world, which mainly concerns patients with breast cancer. Patients should go to Breast Cancer Units, where they can be treated comprehensively, following the latest standards. In Poland, only 9 centres were accredited to meet the BCU requirements. Regardless of the BCU accreditation, the Ministry of Health, together with the public payer, decided to finance separately comprehensive oncological care for beneficiaries with breast cancer under the KON-Pierś system (the requirements and criteria for these centres appear to be less specific and precise compared to the requirements and criteria for centres accredited as BCUs). This gives only 10 additional comprehensive treatment centres ( 1 of them has BCU status). The consequence of this is that the percentage of breast-conserving surgeries is too low, which can be seen from our and other studies [13]. 
TABLE 1. Summary of the interviews with oncology specialists and oncology surgeons

\begin{tabular}{|c|c|c|}
\hline & \multicolumn{2}{|c|}{ Most common opinions given during interviews } \\
\hline & Oncology specialists & Oncology surgeons \\
\hline $\begin{array}{l}\text { Assessment of the breast can- } \\
\text { cer diagnosis system in Poland }\end{array}$ & $\begin{array}{l}\text { - Works well in end-to-end care faci- } \\
\text { lities like Breast Cancer Units (BCU). } \\
\text { - In smaller centres, appropriate } \\
\text { diagnostic standards are often not } \\
\text { applied (e.g. fine-needle biopsy is still } \\
\text { performed instead of core-needle } \\
\text { biopsy) or a full panel of genetic tests } \\
\text { is not ordered. } \\
\text { - There is no clearly defined diagnostic } \\
\text { path, which means that the patient } \\
\text { often „hovers" around the system, } \\
\text { before receiving appropriate help in } \\
\text { the oncology centre. }\end{array}$ & $\begin{array}{l}\text { - It works well in large cancer centres } \\
\text { but doesn't work well in smaller ones. } \\
\text { - There is territorial differentiation, } \\
\text { i.e. patients in large cities with large } \\
\text { oncology centres have a greater chan- } \\
\text { ce of getting the right treatment path } \\
\text { than in smaller ones. } \\
\text { - Differentiation in the quality of breast } \\
\text { ultrasound examinations. They are } \\
\text { often done by people with an insuffi- } \\
\text { cient level of competence in this area. }\end{array}$ \\
\hline $\begin{array}{l}\text { Assessment of the system of } \\
\text { treatment/surgical treatment } \\
\text { of breast cancer in Poland }\end{array}$ & $\begin{array}{l}\text { - Patients generally have good access } \\
\text { to breast cancer treatment but not al- } \\
\text { ways the optimal treatment pathway, } \\
\text { e.g. the patient is not offered neoadju- } \\
\text { vant treatment or does not undergo } \\
\text { a sentinel node biopsy. } \\
\text { - Planning and coordination of care } \\
\text { work well in large centres, but in } \\
\text { smaller ones, they are often fictional } \\
\text { to meet formal requirements. } \\
\text { - The problem is access to high-quality } \\
\text { pathomorphological examinations. } \\
\text { On the one hand, there are too few } \\
\text { doctors of this specialty, on the other } \\
\text { hand, often in less specialized or smal- } \\
\text { ler centres, too few tests are ordered } \\
\text { for „economy" reasons, which deter- } \\
\text { mines suboptimal patient treatment } \\
\text { pathways. }\end{array}$ & $\begin{array}{l}\text { - Patients should be treated compre- } \\
\text { hensively and not randomly (e.g. in } \\
\text { a centre that only offers surgery). } \\
\text { Hence, care must be taken in centres } \\
\text { that can cope with it (BCU type), while } \\
\text { they take place in centres that do } \\
\text { little. } \\
\text { - Access for doctors to high-quality } \\
\text { pathomorphological examinations to } \\
\text { determine the optimal treatment path } \\
\text { for the patient is crucial. For example, } \\
\text { without appropriate diagnostics, } \\
\text { appropriate treatment, including neo- } \\
\text { adjuvant therapy, will not be planned, } \\
\text { or an adequate scale of surgery } \\
\text { (e.g. prophylactic mastectomy) will } \\
\text { not be planned. } \\
\text { - Treatment according to the latest } \\
\text { guidelines is essential, taking into ac- } \\
\text { count all currently available treatment } \\
\text { pathways for patients. Unfortunately, } \\
\text { quite often in some centres, it is } \\
\text { finances that determine the method } \\
\text { of treatment, reducing the chances of } \\
\text { recovery of patients- }\end{array}$ \\
\hline
\end{tabular}

Unfortunately, these less optimistic conclusions coincide with the observations and experiences of Polish patients. The international All.Can survey [14], which comprised almost 1135 patients from Poland, shows that the cancer diagnostics system in Poland is still far from ideal. In $27 \%$ of respondents, cancer was diagnosed as another disease. One in 8 people with cancer (12\%) had to wait for 3 to 6 months for a diagnosis, $6 \%$ waited more than 6 months for a proper diagnosis, and an additional $6 \%$ waited over a year.

The main limitation of the study is the low response rate; nevertheless, during IDIs we managed to obtain detailed and precise information that finally allowed us to obtain conclusive results. Detailed analysis of comprehensive data provided by the Polish NHF regarding the current organization of breast cancer treatment is the core strength of our study. To our knowledge, we are the first to comprehensively analyse systemic data on breast cancer treatment in the Polish female population.

\section{CONCLUSIONS}

A properly selected path of diagnosis and treatment of each patient with breast cancer has an extremely significant impact on their prognosis, survival, and quality of life. Fragmentation of the services we still deal with in Poland is not a desirable situation because in breast 
cancer and many other cancers the gold standard is to provide patients with comprehensive and coordinated care. The possible differences in the treatment pathway for patients with breast cancer are shown by the results of the survey conducted for this report. Mastectomy was the most frequently performed procedure for patients treated with neoadjuvant therapy in $2^{\text {nd }}$-degree hospitals (over $75 \%$ of patients), while surgical conserving treatment was most often performed in cancer hospitals. These results clearly indicate that treatment standards may vary according to the type of hospital. The interviewed experts also emphasized that the differences in the path of diagnosis and treatment are determined by the type of facility the patient attends.

In smaller facilities, it is very difficult to provide full facilities for diagnosing and treating patients under the latest guidelines and standards, which means that the chances of patients treated in smaller centres that are less capable in terms of infrastructure and medical resources are much lower. The data of the Polish payer, as well as information from hospitals and the opinion of experts, indicate that in Poland there is still no oncological care system for patients with breast cancer that provides equal opportunities to patients regardless of their place of residence or selected centre for treatment.

\section{DISCLOSURE}

The authors report no conflict of interest.

\section{References}

1. Kolak A, Kamińska M, Sygit K, Budny A, Surdyka D, KukiełkaBudny B, et al. Primary and secondary prevention of breast cancer. Ann Agric Environ Med 2017; 24 (4): 549-553.

2. Banas T, Juszczyk G, Pitynski K, et al. Incidence and mortality rates in breast, corpus uteri, and ovarian cancers in Poland (1980-2013): an analysis of population-based data in relation socio-economic changes. Onco Targets Ther 2016; 9: 5521-5530.

3. The International Agency for Research on Cancer (IARC). CI5: Cancer Incidence in Five Continents series. Available from: https://ci5.iarc.fr/Default.aspx (accessed: 27 August 2020).

4. WHO. Health statistics and information systems. Available from: https://www.who.int/healthinfo/statistics/mortality_rawdata/en/ (accessed: 27 August 2020).

5. Carioli G, Malvezzi M, Rodriguez T, et al. Trends and predictions to 2020 in breast cancer mortality in Europe. Breast 2017; 36: 89-95.

6. EUROSTAT. Preventable and treatable mortality statistics. Available from: https://ec.europa.eu/eurostat/statisticsexplained/index. php?title=Preventable_and_treatable_mortality_statistics\#Overview (accessed: 2 September 2020).

7. EUSOMA. European Society of Breast Cancer Specialists. Improving Breast Cancer Care in Europe. Available from: https://www. eusoma.org/en/recommendations/1.-107-1 (accessed: 27 August 2020).
8. Rubio IT, Wyld L, Esgueva A, et al. Variability in breast cancer surgery training across Europe: an ESSO-EUSOMA international survey. Eur J Surg Oncol 2019; 45 (4): 567-572.

9. Riss M. Modern surgical treatment of breast cancer. Ann Med Surg (Lond) 2020; 56: 95-107.

10. Osowiecka K, Rucińska M, Nowakowski J, Nawrocki S. How long are cancer patients waiting for oncological therapy in Poland? Int J Environ Res Public Health 2018; 15 (4): 577.

11. Dela R, Dubas-Jakóbczyk K, Kocot E, Sowada Ch. Improving oncological care organization in Poland - the 2015 reform evaluation in the context of European experiences. Int J Health Plann Manage 2019; 34 (1): e100-e110.

12. Supreme Audit Office. Information on the inspection results. Preparation and implementation of the oncology package. Supreme Audit Office, 2017.

13. Grabowska-Kufel J, Radecka B, Streb J, et al. Breast-conserving surgeries in HER-positive breast cancer patients are performed too rarely in Poland. Nowotwory 2020; 70 (6): 225-229.

14. Patient insights on cancer care: opportunities for improving efficiency. Findings from the international All.Can patient survey 2019. Available from: https://www.all-can.org/wp-content/ uploads/2019/07/AllCan_international_patient_survey_findings.pdf (accessed: 27 August 2020).

\section{AUTHORS' CONTRIBUTIONS}

MS, TB, prepared research concept and design of the publication. All authors collected data. TB, WW, JA, JK, OK analysed data and wrote the article. MS, TB, JS, RM, WW critically revised and finally approved it 